\title{
Synthesis and properties of manganese-doped barium titanate
}

\author{
L M ARUNACHALAM ${ }^{\dagger}$, D CHAKRAVORTY ${ }^{\dagger}$ and E C SUBBARAO* \\ Indian Institute of Technology, Kanpur 208016 , India \\ ${ }^{\dagger}$ Present address: Department of Metallurgy. Indian I stitute of Technology, Madras \\ 600036 , India \\ ††Present address: Indian Association for the Cultivation of Science, Calcutta 700032. \\ India \\ *Present address: Tata Research Development and Design Centre, Pune 411 001, India \\ MS received 2 May 1987
}

\begin{abstract}
An oxalate route for the production of $\mathrm{BaTiO}_{3}$ has been modiffed to incorporate $\mathrm{Mn}$ (upto $2 \%$ ) as a dopant and the reaction sequence has been studied. The resulting $\mathrm{Mn}$ doped $\mathrm{BaTiO}_{3}$ exhibits a dielectric constant with an increasing insensitivity to temperature and applied a.c. field as the $\mathrm{Mn}$ content is increased. These samples possess a high electrical resistivity even after treatment in hydrogen at $1100^{\circ} \mathrm{C}$ and are therefore suitable as dielectric for multilayer capacitors with base metal electrodes.
\end{abstract}

Keywords. Mn-doping: domain stabilization; base metal electrodes; barium titanate; oxalate route; capacitors.

\section{Introduction}

Barium titanate $\left(\mathrm{BaTiO}_{3}\right)$ is by far the most extensively studied ceramic dielectric material (Jona and Shirane 1962). Conventional ceramic processing poses problems for the preparation of reproducible, high purity $\mathrm{BaTiO}_{3}$ and for the incorporation of small amounts of desired impurities. Clabaugh et al (1956) described a method to prepare the high purity $\mathrm{BaTiO}_{3}$ from barium titanyl oxalate tetrahydrate (BTO) and Desu (1979) had adapted this route to incorporate small amounts of manganese into $\mathrm{BaTiO}_{3}$.

The rapidly escalating cost of established silver electrodes for the ceramic capacitors has forced the use of base metals such as nickel as electrode. However, a disc or multilayer capacitor with nickel electrode has to be heat-treated in a low oxygen content atmosphere to prevent the oxidation of nickel. Under these conditions (of low $\mathrm{P}_{\mathrm{O}}$, and high temperature), $\mathrm{BaTiO}_{3}$ becomes conducting due to the formation of $\mathrm{Ti}^{3+}$ ions accompanying the creation of oxygen ion vacancies. It has been found that the incorporation of $\mathrm{Mn}$ into $\mathrm{BaTiO}_{3}$ lattice prevents the reduction of $\mathrm{BaTiO}_{3}$ when it is fired in an atmosphere reducing enough to inhibit the oxidation of $\mathrm{Ni}$ (Ainger and Herbert 1959; Herbert 1963, 1965; Burn and Meher 1975; Daniels 1976; Burn 1978, 1979; Hagemann 1978a, b; Desu 1979; Subbarao 1979; Hagemann and Ihrig 1979; Desu and Subbarao 1980a, b).

Manganese can exist in three valences: $2^{+}, 3^{+}$and $4^{+}$. The oxygen vacancy concentration on incorporation of $\mathrm{Mn}$ into $\mathrm{BaTiO}_{3}$ varies with the valency of $\mathrm{Mn}$ as follows:

$\therefore$ To whom all correspondence should be addressed. 


$$
\begin{aligned}
\mathrm{BaTi}_{1-x} \mathrm{Mn}_{x}^{4+} \mathrm{O}_{3} & \rightarrow \mathrm{BaTi}_{1-x} \mathrm{Mn}_{x}^{3+} \mathrm{O}_{3-(x / 2)}+\frac{x}{4} \mathrm{O}_{2} \uparrow \\
& \rightarrow \mathrm{BaTi}_{1-x} \mathrm{Mn}_{x}^{2+} \mathrm{O}_{3-x}+\frac{x}{2} \mathrm{O}_{2} \uparrow
\end{aligned}
$$

The presence of oxygen ion vacancies in reduced, undoped $\mathrm{BaTiO}_{3}$ was found to decrease the Curie temperature (by $40-50^{\circ} \mathrm{C}$ for every $10^{20}$ oxygen ion vacancies $\mathrm{cm}^{-3}$ ) (Hardtl and Wernicke 1972) and enhance the dielectric losses. On the other hand, incorporation of $\mathrm{Mn}$ in the $\mathrm{Ti}^{4+}$ site in $\mathrm{BaTiO}_{3}$ was reported to decrease the Curie temperature by $10^{\circ} \mathrm{C} / 1 \% \mathrm{Mn}$ when sintered in an air atmosphere and by 40 $50^{\circ} \mathrm{C} / 1 \% \mathrm{Mn}$ when sintered in low oxygen atmosphere $\left(\mathrm{P}_{\mathrm{O}_{2}} \simeq 10^{-12}\right)$ (Hagemann 1978a; Burn 1979; Hagemann and Ihrig 1979). At the same time, Mn addition reduces the permittivity and loss factor (Burn 1979).

Since $\mathrm{Mn}$-doped $\mathrm{BaTiO}_{3}$ has been found to be the most satisfactory dielectric for capacitors with base metal electrodes (BME), a detailed study was undertaken in the present work to establish the mechanism underlying the proper incorporation and amount of $\mathrm{Mn}$ into the $\mathrm{BaTiO}_{3}$ lattice, so that the desired dielectric properties (high resistivity, low $\tan \delta$, low dependence of permittivity on applied a.c. field and on temperature etc) for this application could be achieved.

\section{Experimental}

\subsection{Materials}

The raw materials used were barium chloride dihydrate and oxalic acid dihydrate (both from Sarabhai Chemicals), titanium tetrachloride and manganese carbonate (from Reidel de Haven, Germany). All of them are more than $99.5 \%$ pure. Either distilled or deionized water was used for preparing the solutions.

\subsection{Specimen preparation}

High purity $\mathrm{BaTiO}_{3}$ and manganese-doped $\mathrm{BaTiO}_{3}$ were prepared from the complex barium titanyl oxalate and manganese-doped barium titanyl oxalate respectively. A mixed solution of barium chloride and titanium tetrachloride was allowed to drip slowly into a hot $\left(80-85^{\circ} \mathrm{C}\right)$ vigorously stirred solution of oxalic acid. The precipitated oxalate was filtered hot, washed several times with distilled water and acetone, and air-dried at $150^{\circ} \mathrm{C}$. The precipitate was calcined at $900^{\circ} \mathrm{C}$ for $2 \mathrm{hr}$ and care was taken to remove the chloride ions from the calcined powder.

The calcined powder was mixed with about $4 \mathrm{wt} \%$ of $25 \%$ polyvinyl acetate solution, dried and pressed under a hydraulic pressure of $5 \mathrm{kbar}(75,000 \mathrm{psi})$ into cylindrical discs of either $12.5 \mathrm{~mm}$ or $9 \mathrm{~mm}$ dia. Sintering was carried out in air at $1350^{\circ} \mathrm{C}$ for $2 \mathrm{hr}$. The power to the furnace was switched off during cooling. For the domain stabilization studies, the dises were annealed in two different conditions: (i) in ultra-high pure argon at $800^{\circ} \mathrm{C}$ for $10 \mathrm{~min}$ with furnace cooling and (ii) in air at $1100^{\circ} \mathrm{C}$ for $10 \mathrm{~min}$ and quenched to room temperature to establish the oxygen defect 
equilibria within the system. To define the conditions suitable for the $\mathrm{BME}$ capacitors, the discs were annealed in $\mathrm{H}_{2}$ at $1100^{\circ} \mathrm{C}$ for 10 min with furnace cooling. For capacitance and resistivity measurements, all the discs were polished to obtain clean and parallel surfaces and electroded with air-dry silver paint.

\subsection{Characterization}

The DTA and TGA studies were carried out on a MOM derivatograph. The IR spectra were obtained on a Perkin Elmer 580 spectrometer. The X-ray diffraction data were recorded on a Philips diffractometer using $\mathrm{CuK}_{\alpha}$ radiation. The dielectric properties were measured on a General Radio 1620-A capacitance bridge assembly. The electrical resistivity was measured on a General Radio 1650-A impedance bridge and a General Radio megaohm bridge.

\section{Results and discussion}

A method for effectively incorporating $\mathrm{Mn}$ into $\mathrm{BaTiO}_{3}$ lattice and the dielectric behaviour of the resulting compositions are presented here.

\subsection{Preparation of $\mathrm{Mn}$-doped $\mathrm{BaTiO}_{3}$}

3.1 a Pure $\mathrm{BaTiO}_{3}$ : To start with, pure $\mathrm{BaTiO}_{3}$ was prepared by the $\mathrm{BTO}$ route, following the method of Clabaugh et al (1956) and was subjected to a DTA/TGA study (figure 1). A number of reaction schemes have been proposed for the decomposition of BTO to $\mathrm{BaTiO}_{3}$ (Saburi 1959; Strizbkov et al 1960; Gallagher and Schery 1963; Gallagher and Thomson 1965; Gopalakrishna Murthy et al 1975). The present results did not fit any of these schemes and could be explained only by the reaction sequence proposed below:

$$
\begin{aligned}
& \mathrm{BaTiO}\left(\mathrm{C}_{2} \mathrm{O}_{4}\right)_{2} \cdot 4 \mathrm{H}_{2} \mathrm{O} \frac{\text { upto } 250^{\circ} \mathrm{C}}{-\left(4 \mathrm{H}_{2} \mathrm{O}, \mathrm{CO}\right)} \mathrm{BaTiO}\left(\mathrm{C}_{2} \mathrm{O}_{4}\right) \cdot \mathrm{CO}_{2} \cdot \frac{1}{2} \mathrm{O}_{2} \\
& \stackrel{400 \mathrm{C}}{-3 \mathrm{CO}} \mathrm{BaTiO} \cdot 2 \mathrm{O}_{2} \frac{800^{\circ} \mathrm{C}}{-\mathrm{O}_{2}} \mathrm{BaTiO}_{3} .
\end{aligned}
$$

The weight losses calculated from (3) are compared with the observed values at different temperature ranges (table 1) which substantiate the above reaction sequence. The $x$-ray pattern of the calcined material showed the expected tetragonal $\mathrm{BaTiO}_{3}$ phase only. The room temperature dielectric constant of this material, after calcination and sintering, was high (about 4000) suggesting fine grain size.

3.1b Mn-doped $\mathrm{BaTiO}_{3}$ - Method 1: In a minor modification of Clabaugh et al's (1956) method, solutions of chlorides of barium, titanium and manganese were mixed in requisite proportion, and the mixed solution was added drop-wise to the oxalic acid solution. The precipitate was white, as in the case of undoped BTO. Compared to the instantaneous precipitation of pure BTO when drops of the chloride solutions 


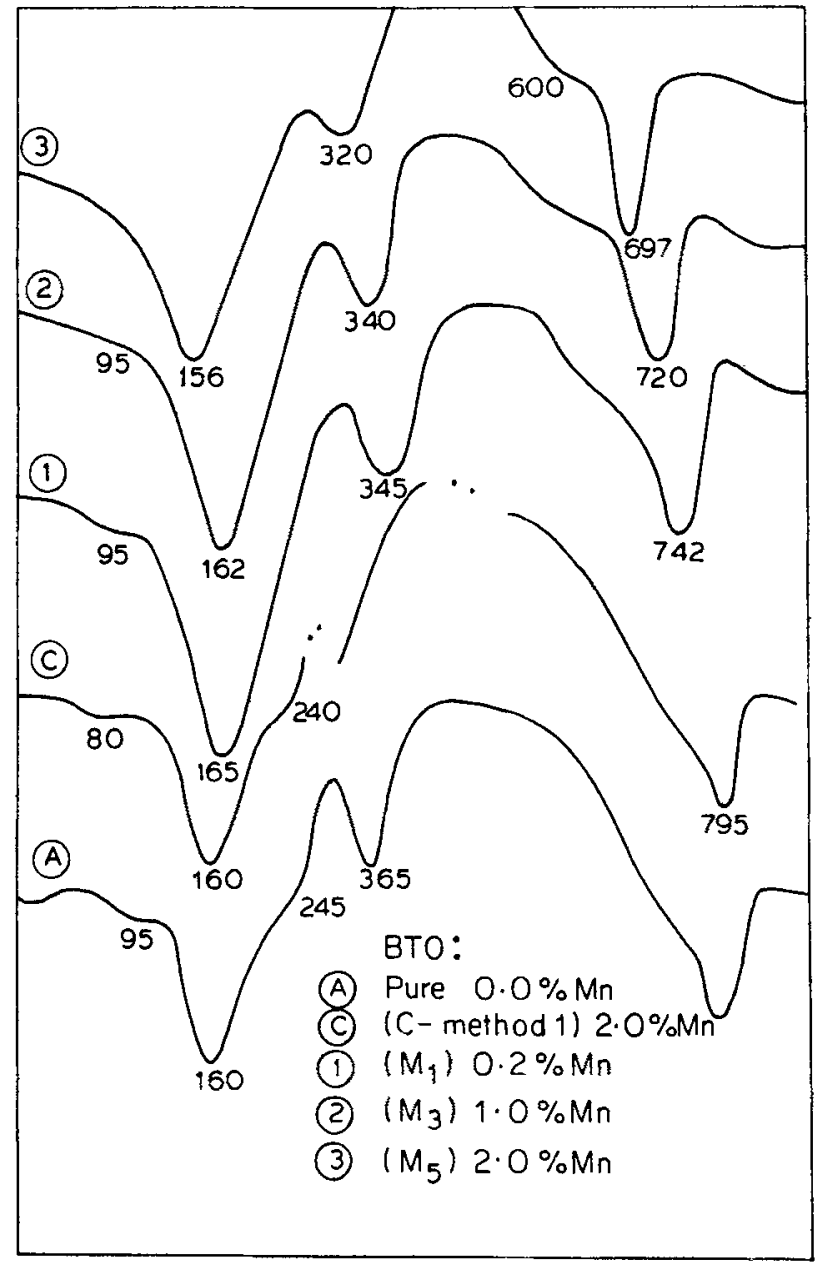

Figure 1. DTA of pure and Mn-doped barium titanyl oxalates.

Table 1. Comparison of the weight losses of BTO, observed and calculated.

\begin{tabular}{|c|c|c|c|}
\hline \multirow[b]{2}{*}{ Decomposition } & \multicolumn{2}{|c|}{ Weight loss ("\%) } & \multirow{2}{*}{$\begin{array}{c}\text { Temperature } \\
\left({ }^{\circ} \mathrm{C}\right)\end{array}$} \\
\hline & Calculated & Observed & \\
\hline $\begin{array}{c}\text { Dehydration of BTO } \\
\text { and low temperature } \\
\text { decomposition of BTO }\end{array}$ & $22 \cdot 24$ & $20 \cdot 25$ & Upto 250 \\
\hline $\begin{array}{l}\text { Main oxalate decom- } \\
\text { position }\end{array}$ & 18.69 & $19 \cdot 50$ & About 400 \\
\hline $\begin{array}{l}\text { Final decomposition to } \\
\text { BaTiO }_{3}\end{array}$ & $7 \cdot 11$ & $6 \cdot 75$ & About 800 \\
\hline Total weight loss & $48 \cdot 09$ & $46 \cdot 50$ & - \\
\hline
\end{tabular}


touched the oxalate solution, there was a delay in the start of the precipitate formation when $\mathrm{Mn}$ was present in the chloride mixture added to oxalic acid. This observation is discussed later. The DTA and IR study did not reveal any difference between the doped and undoped BTO, raising a doubt as to whether Mn was at all incorporated in the $\mathrm{BaTiO}_{3}$ lattice at this stage. However, the doped samples, after calcination and sintering, did exhibit a brown colour. The room temperature dielectric constant of $1 \% \mathrm{Mn}$ sample was higher than that of the undoped and the $2 \%$ $\mathrm{Mn}$-doped samples (figure 2). This behaviour may be contrasted with the steady decrease in dielectric constant with $\mathrm{Mn}$ content when the samples are prepared from $\mathrm{BaCO}_{3}+\mathrm{TiO}_{2}+\mathrm{MnCO}_{3}$ by conventional ceramic processing but the trend is comparable to samples of $\mathrm{BaTiO}_{3}$ doped with $\mathrm{La}$, which is known to be a donor impurity (Hagemann 1978a) (figure 2). These higher values may be due to the donor mode of $\mathrm{Mn}$ incorporation or due to grain growth inhibition by $\mathrm{Mn}$ oxides present at grain boundaries. The Curie temperature of the three samples is nearly the same. These confusing set of results raise a question about the presence of $\mathrm{Mn}$ in $\mathrm{BaTiO}_{3}$, its location, valence state and amount. The following experiments were undertaken to throw light on these issues.

3.1c Mn-doped $\mathrm{BaTiO}_{3}$-..-Experiments leading to Method 2: In the first experiment, barium oxalate was precipitated by adding barium chloride sclution, drop-wise to the oxalic acid solution. To this precipitate $\mathrm{MnCl}_{2}$ solution was added drop-wise, when it was observed that gradually the entire barium oxalate precipitate disappeared, leaving a clear solution.

In the second experiment, hydrated titanyl oxalate was formed by adding the $\mathrm{TiCl}_{4}$ solution, drop-wise to oxalic acid solution. To this precipitate was added a solution of manganese chloride or carbonate drop-wise when the itanyl oxalate precipitate was found to partially redissolve.

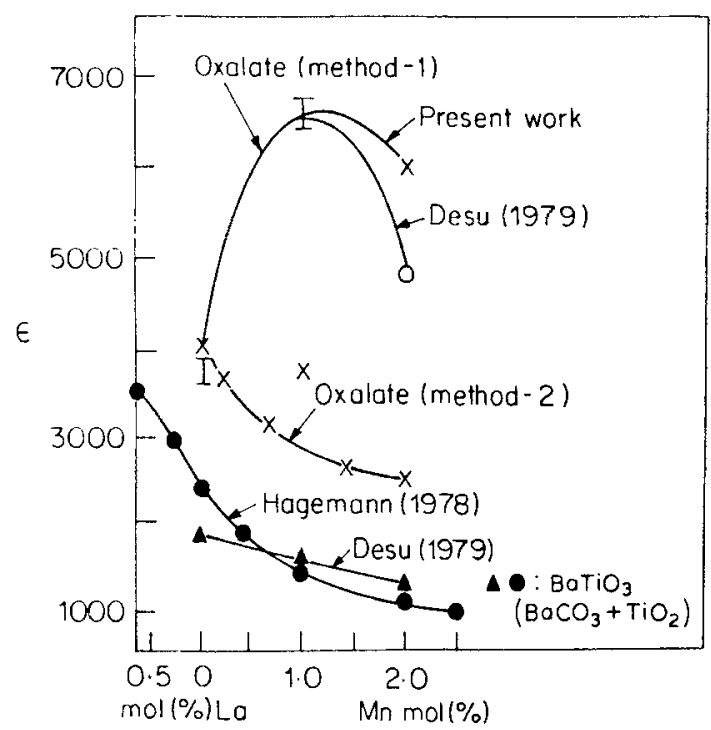

Figure 2. Variation of room temperature permittivity of $\mathrm{BaTiO}_{3}$ with concentration of $\mathrm{La}$ and Mn dopant. 
The dissolution of the barium and titanyl oxalate precipitates on coming into contact with $\mathrm{MnCl}_{2}$ or manganese oxalate explains the delay in precipitate formation when chlorides of $\mathrm{Ba}$, Ti and $\mathrm{Mn}$ were added to oxalate, referred to in the first method.

In the third experiment, $\mathrm{TiCl}_{4}$ was added drop-wise to the clear solution containing $\mathrm{Ba}$ and $\mathrm{Mn}$ oxalates, described in the first experiment above. There was an instant reddish brown colour and reddish brown precipitate simultaneously formed. This is in sharp contrast to the white precipitate obtained when a mixture of all the three chlorides is added to the oxalic solution in the first method. The formation of a coloured precipitate may be indicative of the incorporation of $\mathrm{Mn}$ into the $\mathrm{BaTiO}_{3}$ lattice.

Based on the insight gained from the above three experiments, the final compositions used in the present study were prepared as follows (designated as method 2). A requisite amount of $\mathrm{MnCl}_{2}$ solution was added to the oxalic acid solution. To this, a mixture of $\mathrm{Ba}$ and $\mathrm{Ti}$ chlorides was added drop-wise. A reddish brown precipitate was formed, the intensity of the colour increasing with increasing $\mathrm{Mn}$ content. These samples are designated $\mathrm{M}_{1}$ to $\mathrm{M}_{5}$ containing $0.2,0.6,1.0,1.4$ and $2.0 \% \mathrm{Mn}$ respectively.

All the DTA peaks are gradually shifted to lower temperatures as $\mathrm{Mn}$ concentration increases from $0(\mathrm{~A})$ to $2 \%\left(\mathrm{M}_{5}\right)$, except the dehydration peak at about $160^{\circ} \mathrm{C}$ (figure 1). The small peaks at $95^{\circ}$ and $245^{\circ} \mathrm{C}$ in pure BTO gradually disappear in samples with increasing $\mathrm{Mn}$ content. A peak whose sharpness increases with $\mathrm{Mn}$ content appears at about $600^{\circ} \mathrm{C}$ in $\mathrm{Mn}$-doped samples and is attributed to the oxidation of lower oxides of $\mathrm{Mn}$ to $\mathrm{Mn}_{2} \mathrm{O}_{3}$. The Ti-O peak in the IR spectra appears at $507 \mathrm{~cm}^{-1}$ in pure BTO (A) and at $520 \mathrm{~cm}^{-1}$ in $\mathrm{M}_{5}$ (containing $2 \% \mathrm{Mn}$ ).

The shifts in DTA peaks and IR spectra, as well as colouring of the precipitate prepared by the second method is in sharp contrast to the data for samples prepared by the first method, suggesting that $\mathrm{Mn}$ is indeed incorporated in BTO prepared by the second method. Further confirmation is provided by the steady decrease in room temperature dielectric constant with $\mathrm{Mn}$ content, similar to the trend observed by Hagemann (1978a) and Desu (1979) for Mn-doped $\mathrm{BaTiO}_{3}$ prepared from $\mathrm{BaCO}_{3}+\mathrm{TiO}_{2}$ (figure 2). Hagemann (1978a) reported that donor impurities (e.g. La) increases the dielectric constant of $\mathrm{BaTiO}_{3}$ while acceptor type impurities (e.g. Fe, $\mathrm{Mn}$ ) decrease the same, which suggests that $\mathrm{Mn}$ is in the acceptor mode in samples prepared by the second method.

The X-ray diffraction patterns are unaffected by $\mathrm{Mn}$ addition (upto $2 \%$ studied). With $2 \% \mathrm{Mn}$ addition, the Curie temperature decreased by $5^{\circ} \mathrm{C}$, when the samples were sintered in air or oxygen but decreased by about $15^{\circ} \mathrm{C}$ when the samples were sintered and quenched in argon $\left(\mathrm{P}_{\mathrm{O}_{2}}=10^{-12} \mathrm{~atm}\right)$. The trend of variation of $T_{c}$ with $\mathrm{Mn}$ addition and with $\mathrm{P}_{\mathrm{O}_{2}}$ observed here is in agreement with the earlier reports (Hagemann 1978a; Burn 1979; Hagemann and Ihrig 1979) but the magnitude of change obtained in the present work is smaller.

\subsection{Dielectric behaviour of $\mathrm{Mn}$-doped $\mathrm{BaTiO}_{3}$}

3.2a Variation with temperature: The temperature dependence of dielectric constant of pure $(A)$ and $\mathrm{Mn}$-doped $\mathrm{BaTiO}_{3}\left(\mathrm{M}_{1}\right.$ to $\left.\mathrm{M}_{5}\right)$ prepared by the second method is shown in figure 3 . The dielectric constant at all temperatures decreases 


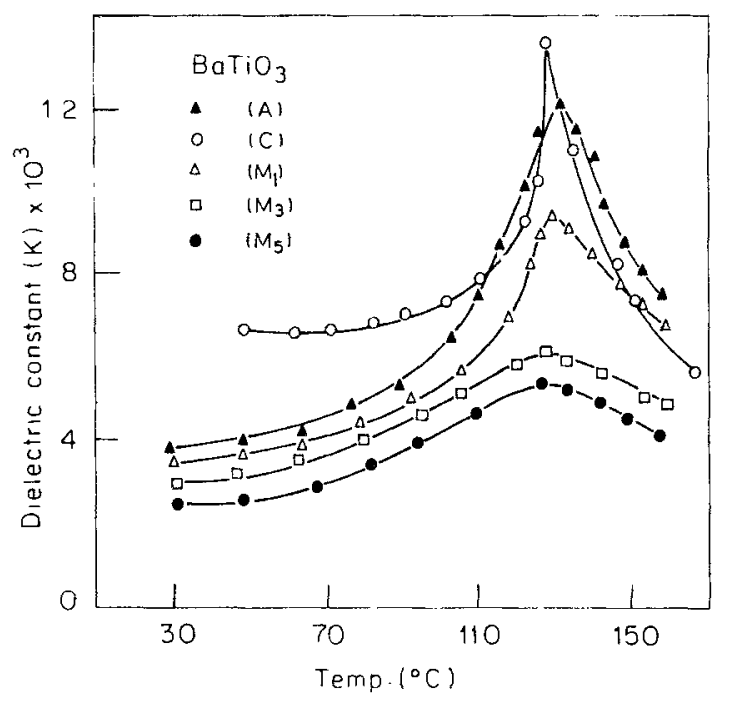

Figure 3. Varkation of dielectric constant of $\mathrm{Mn}$-doped $\mathrm{BaTiO}_{3}$ with temperature.

with $\mathrm{Mn}$ content. However, for sample $\mathrm{C}$ containing $2 \% \mathrm{Mn}$, made by the first method, not only is the dielectric constant at room temperature very high but at Curie point exhibits a sharp peak, suggesting that $\mathrm{Mn}$ may be serving as a grain growth inhibitor or as a donor impurity in these samples. The Curie temperatures shift by only a small amount with $\mathrm{Mn}$ content.

3.2b Variation with a.c. field: Besides the stability of dielectric constant with temperature change discussed above. another important property sought in a multilayer capacitor material is the stability of dielectric constant with applied a.c. field. The change in dielectric constant (at room temperature) with applied a.c. field (upto $500 \mathrm{~V} / \mathrm{cm}$ ) for samples of pure $(\mathrm{A})$ and $\mathrm{Mn}$-doped $\mathrm{BaTiO}_{3}\left(\mathrm{M}_{1}\right.$ to $\mathrm{M}_{5}$ ) prepared by the second method is shown in figure 4 . The susceptibility of dielectric constant to applied a.c. field decreases remarkably with increasing $\mathrm{Mn}$ content. This trend can be further enhanced by quenching the samples from a high temperature in air atmosphere (e.g. $1100 \mathrm{C}$ ) (figure $4 \mathrm{a}$ ) or by sintering and quenching samples from $1300 \mathrm{C}$ in argon $\left(\mathrm{P}_{\mathrm{O}_{2}}=10^{-12} \mathrm{~atm}\right.$.) (figure $4 \mathrm{~b}$ ). On the other hand, sintering and quenching from a high temperature in oxygen atmosphere was more deleterious than treatment in air with or without quenching (figure $4 b$ ). The corresponding changes in dielectric loss $(\tan d)$ are shown in figures $5 a$ and $5 b$.

The importance of proper preparation method is demonstrated strikingly by comparing the samples $C$ (prepared by the first method) and $\mathrm{M}_{5}$ (prepared by the second method), both containing $2^{\circ}{ }_{0} \mathrm{Mn}$, as far as the effect of the a.c. field on their dielectric constant is concerned (figure 4). With normal furnace cooling or quenching from high temperatures, sample $C$ exhibited a dielectric behaviour close to that of undoped sample $(A)$. Only on heat treating under low $P_{O_{2}}\left(10^{-12} \mathrm{~atm}\right.$.) did this sample exhibit an acceptable dielectric response to the applied a.c. field.

The insensitivity of the dielectric constant to the applied a.c. field has been termed by Hagemann (1978) as domain stabilization, which is brought about by the formation of a transition metal (e.g. Mn)-oxygen ion vacancy $\left(\mathrm{TM}-\mathrm{V}_{0}\right.$ ) assemblies (Lambeck and 

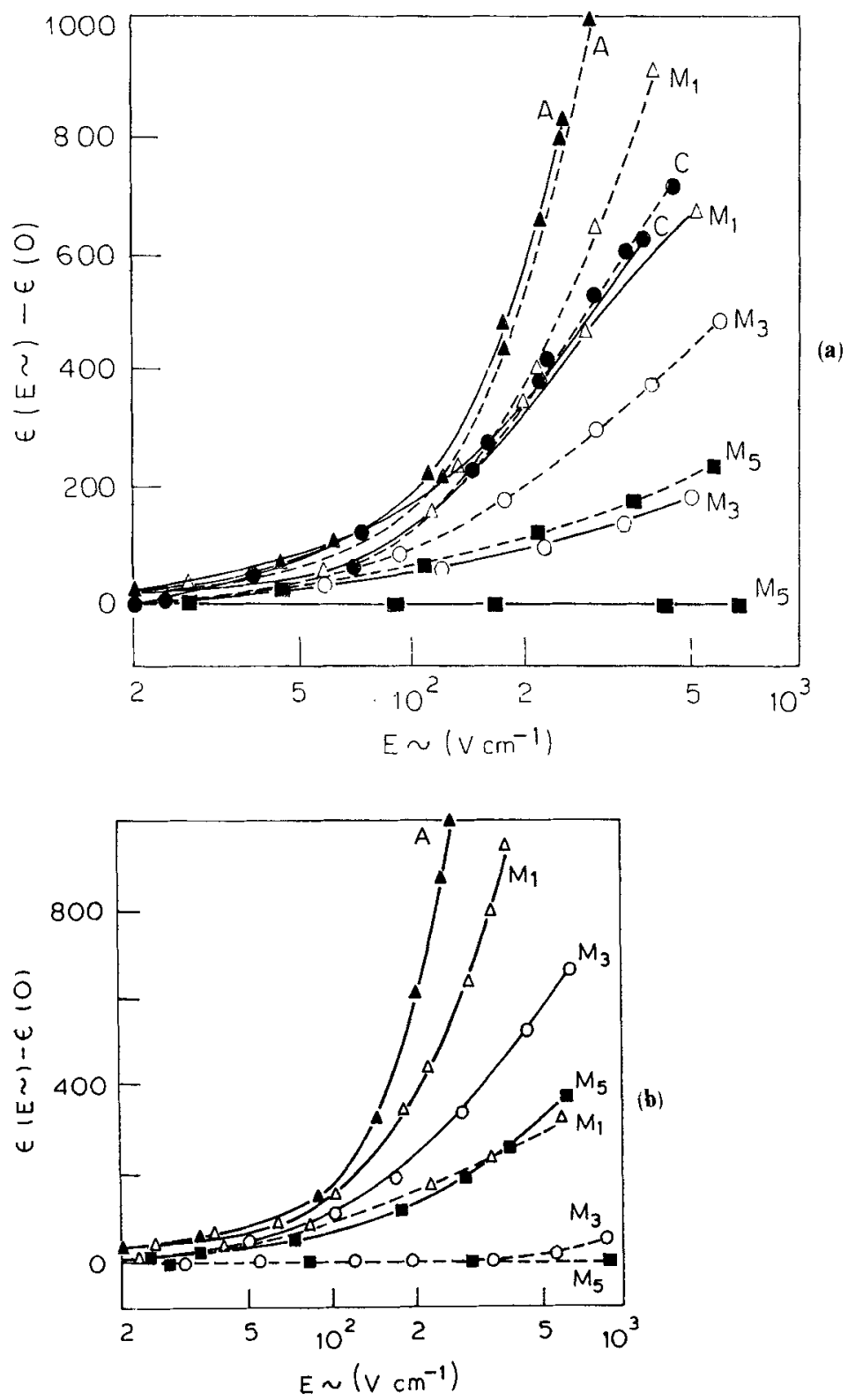

Figure 4. Dependence of $\delta$ of $\mathrm{Mn}$-doped $\mathrm{BaTiO}_{3}$ on the amplitude of the external a.c. field $\left(T=28^{\circ} \mathrm{C}, f=1 \mathrm{kHz}\right)$. a. Sintered in air, with and without annealing (-----) and quenched in air (-). b. Sintered, annealed and quenched in argon (---.-) and in oxygen (-).

Jonker 1978). The formation of these assemblies is facilitated by the presence of $\mathrm{Mn}$ of a lower valency in $\mathrm{Ti}^{4+}$ sites in the $\mathrm{BaTiO}_{3}$ lattice and an enhanced concentration of oxygen ion vacancies. These processes are clearly favoured by quenching from ingh temperatures in air but not in oxygen (to retain the higher equilibrium defect concentration corresponding to that temperature) and by heat treating at low $\mathrm{P}_{\mathrm{O}_{2}}$, thus accounting for the observed dielectric behaviour. 


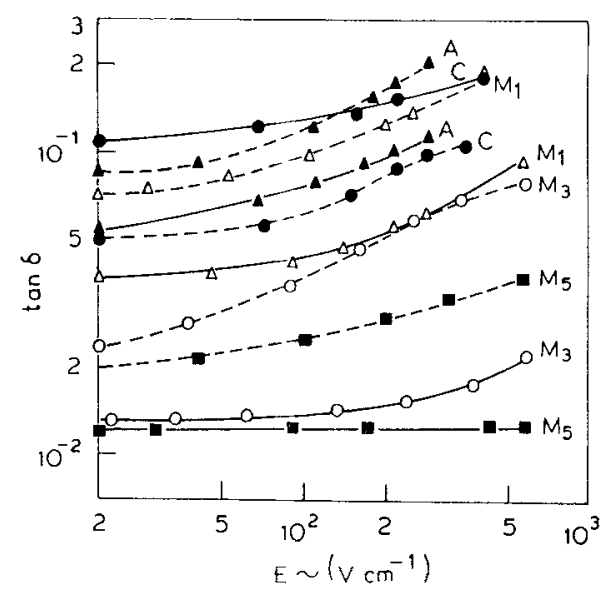

(a)

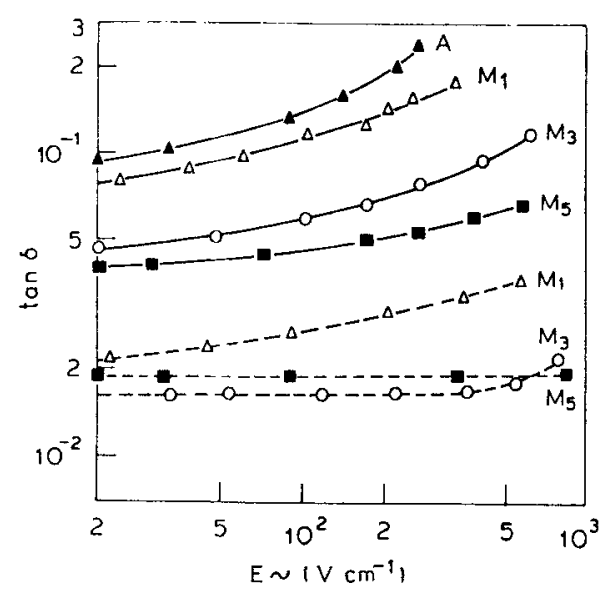

(b)

Figure 5. Dependence of $\tan \delta$ of Mn-doped $\mathrm{BaTiO}_{3}$ on the amplitude of the external a.c. field $(T=28 \mathrm{C}, f=1 \mathrm{kHz})$. a. Sintered in air, with and without annealing (---- ) and

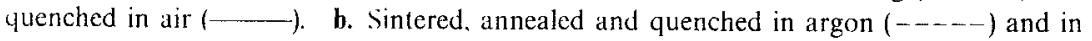
oxygen (-....).

3.2c Behatiour in hydrogen atmosphere: A multilayer capacitor with base metal electrodes is fired in a reducing atmosphere (with a very low $\mathrm{P}_{\mathrm{O}_{2}}$ ) to prevent the oxidation of the base metal (e.g. Ni). Under these conditions, the dielectric material should not get reduced i.e. it should sufficiently retain the bigh electrical resistivity. For this purpose, the samples were subjected to a harsher treatment by exposing them to pure hydrogen at $900^{\circ} \mathrm{C}$ and $1100^{\circ} \mathrm{C}$ and cooling them in the same atmosphere. The electrical resistivity, dielectric constant and $\tan \delta$ of these samples at room temperature are listed in table 2. Clearly, the incorporation of $\mathrm{Mn}(\sim 0.6 \%)$ ensures an adequate electrical resistivity of $\mathrm{BaTiO}_{3}$ samples even under these extreme conditions employed.

\section{Conclusions}

(i) A proper preparation method is essential to achieve the necessary dielectric properties of ceramic $\mathrm{BaTiO}_{3}$ for use with base metal electrodes. (ii) A method has

Table 2. Effect of annealing in $\mathrm{H}_{2}, 900^{\circ} \mathrm{C} / 10 \mathrm{~min}$ and $1100^{\circ} \mathrm{C} / 10 \mathrm{~min}$ on electrical resistivity $(\rho)$, dielectric constant $(K)$ and dielectric loss ( $\tan \delta)$.

\begin{tabular}{|c|c|c|c|c|c|c|}
\hline \multirow{2}{*}{$\begin{array}{l}\text { Compositions } \\
(1 / \% \mathrm{Mn})\end{array}$} & \multicolumn{3}{|c|}{$900 \mathrm{C} / 10 \mathrm{~min}}$. & \multicolumn{3}{|c|}{$1100^{\circ} \mathrm{C} / 10 \mathrm{~min}}$. \\
\hline & $\log \rho$ & K & $\tan \delta$ & $\log p$ & $\mathrm{~K}$ & $\tan \delta$ \\
\hline $\mathrm{A}(0)$ & 50 & 2900 & 0.15 & 20 & - & - \\
\hline $\mathrm{M}_{1}(0 \cdot 2)$ & $5 \cdot 0$ & 2140 & $0 \cdot 15$ & $3 \cdot 5$ & - & - \\
\hline$M_{2}(0 \cdot 6)$ & $8 \cdot 2$ & 2450 & 0.09 & $7 \cdot 0$ & 1975 & 0.15 \\
\hline$M_{3}(1 \cdot 0)$ & $8 \cdot 2$ & 2520 & $0 \cdot 07$ & $7 \cdot 5$ & 2400 & $0 \cdot 12$ \\
\hline$M_{4}(1 \cdot 4)$ & $9 \cdot 0$ & 2750 & 0.07 & $8 \cdot 0$ & 2520 & $0 \cdot 10$ \\
\hline $\mathrm{M}_{5}(2 \cdot 0)$ & $9 \cdot 0$ & 3500 & $0 \cdot 06$ & $8 \cdot 2$ & 2600 & 0.10 \\
\hline
\end{tabular}


also been developed to incorporate $\mathrm{Mn}$ into the $\mathrm{BaTiO}_{3}$ lattice, by modifying the barium titanyl oxalate route. (iii) The $\mathrm{Mn}$-doped $\mathrm{BaTiO}_{3}$ prepared in this manner exhibits dielectric properties which are relatively insensitive to temperature and applied a.c. field (upto $500 \mathrm{~V} / \mathrm{cm}$ ) and possesses a high electrical resistivity even after treatment in $\mathrm{H}_{2}$ at $1100^{\circ} \mathrm{C}$ and thereby is eminently suitable for multilayer capacitors with base metal electrodes. (iv) The dielectric constant is insensitive to the applied a.c. field if the samples are quenched from $1300^{\circ} \mathrm{C}$ in air atmosphere (but not in oxygen) or are given a heat treatment at a low $\mathrm{P}_{\mathrm{O}_{2}}$ at the same temperature.

\section{Acknowledgements}

The authors are grateful to Mrs T A Padmavathi Sankar, Mr V P Srivastava, Mr S C Barthwal and $\mathrm{Mr} \mathrm{K}$ Umesh Kumar for their assistance and to the Department of Electronics, Government of India, for financial support.

\section{References}

Ainger F W and Herbert J M 1959 Trans. Br. Ceram. Soc. 58410

Burn I 1978 Am. Ceram. Soc. Bull. 57600

Burn I 1979 J. Mater. Sci. 142453

Burn I and Meher G H 1975 J. Mater. Sci. 10633

Clabaugh W S, Swiggard E M and Gilchrist R 1956 J. Res. Natl. Bur. Stand. 56289

Daniels J M 1976 Philips Res. Rep. 31505

Desu S B 1979 M. Tech. Thesis. IIT, Kanpur

Desu S B and Subbarao E C 1980a J. Mater. Sci. 152113

Desu S B and Subbarao E C. 1980b Adv. Ceram. 1189

Gallagher P K and Schery F 1963 J. Am. Ceram. Soc. 46567

Gallagher P K and Thomson J 1965 J. Am. Ceram. Soc. 48644

Gopalakrishna Murthy H S, Subbarao N and Narayan Kutty T R 1975 J. Inory. Nuct. Chem. 37891

Hagemann H J 1978a J. Phys. C11 3333

Hagemann H J 1978b Ber. deut. Keram. Ges. 55353

Hagemann H J and Ihrig H 1979 Phys. Rev. B20 3871

Härdtl K H and Wernicke R 1972 Solid State Commun. 10153

Herbert J M 1963 Trans. Br. Ceram. Soc. 62645

Herbert J M 1965 Proc. IEE 1221474

Jona F and Shirane G 1962 Ferroelectric crystals (London: Pergamon Press)

Lambeck P V and Jonker G H 1978 Ferroelectrics 22729

Saburi O 1959 J. Phys. Soc. Jpn. 141159

Strizbkov B V, Lapitskiv A V and Blasov L G 1960 Zh. Prikla. Khim. 332009

Subbarao E C 1979 Proc. symp. sintering and sintered products (Bombay: DAE) p. 1 